
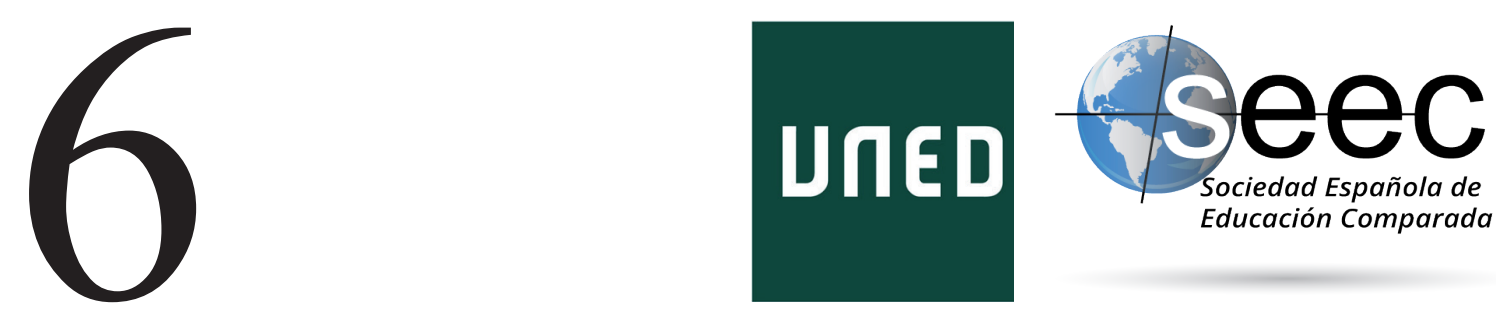

\title{
Optimism Beyond the Problems: BRICS Higher Education Cooperation from a Chinese Perspective
}

Optimismo más allá de problemas: la cooperación de BRICS en educación superior desde la perspectiva china

\section{Jin Sun*; Aiyi Yang**}

DOI: $10.5944 /$ reec.39.2021.29840

Recibido: 7 de febrero de 2021 Aceptado: 11 de mayo de 2021

\footnotetext{
* Jin Sun: Professor of Institute of International and Comparative Education, Beijing Normal University, Beijing, PR China. Main research interests: Education in China and Germany, theories and methods in comparative education, global educational governance, intercultural competence. Datos de contacto: E-mail: jin.sun@bnu.edu.cn

** AryI YANG: Ph.D. Candidate of Institute of International and Comparative Education, Beijing Normal University, Beijing, PR China. Main research interests: International and comparative education, education in China and Spain. Datos de contacto: E-mail: 202031010022@mail.bnu.edu.cn
} 


\begin{abstract}
Multilateral cooperation in higher education among BRICS countries has been under way for 7 years, since 2013. Scholars have different views and judgments, some positive and optimistic, some negative and pessimistic, regarding the significance, progress and prospects of BRICS higher education cooperation (BRICS HEC). What are the views and judgments of participants from Chinese universities? This question has not yet been answered due to a lack of relevant empirical research. To answer this question, six experts in Chinese universities who are involved in organizing or/and researching BRICS HEC were interviewed in this study. The study found that the six experts clearly recognized the necessity and significance of BRICS HEC. They identified the main achievements of this cooperation, including the establishment of two cooperation platforms (i.e., the BRICS Network University and the BRICS University League) and the development of a series of collaborations in student exchanges and research. They also pointed out existing problems, such as the difficulty of achieving multilateral cooperation, difficulty of establishing the mutual recognition of credits and qualifications, and the insufficient enthusiasm among potential participants. Despite these problems, five of the six experts evaluated the progress of such cooperation positively and were optimistic about its prospects. The positive and optimistic views of Chinese experts are contrasted with the problems, obstacles and pessimistic expectations dominant in previous studies, indicating that BRICS HEC is not only supported by the Chinese government but also accepted by Chinese participants. This constitutes an important driving force for the sustainable development of BRICS HEC in the future.
\end{abstract}

Keywords: BRICS countries; higher education cooperation; BRICS Network University; China

\title{
Resumen
}

La cooperación multilateral en educación superior entre los países BRICS se ha llevado a cabo durante 7 años, desde 2013. Los académicos tienen diferentes puntos de vista y juicios cerca de la importancia, el progreso y las perspectivas de la cooperación en educación superior entre los BRICS (CES BRICS), algunos positivos y optimistas, otros negativos y pesimistas. ¿Cuáles son las opiniones y juicios de los participantes de las universidades chinas? Esta pregunta aún no ha sido respondida por la falta de investigación empírica relevante. Para responderla, en este estudio se entrevistó a seis expertos de las universidades chinas que participan en la organización o investigación de CES BRICS, comprobando que los seis expertos reconocían completamente la necesidad y la importancia de cooperación. Identificaron los logros principales de la cooperación, incluido el establecimiento de dos proyectos (la Universidad de Red de BRICS y la Liga de Universidades de BRICS) y el desarrollo de una serie de cooperación en el intercambio de estudiantes y en la investigación científica. También señalaron los problemas existentes, como las dificultades de cooperación multilateral y de confirmación mutua de créditos y calificaciones, y el entusiasmo insuficiente entre los posibles participantes. A pesar de estos problemas, cinco de los seis expertos hicieron comentarios positivos sobre el progreso de dicha cooperación y se mostraron optimistas sobre sus perspectivas. Las opiniones positivas y optimistas de los expertos chinos se contrastan con los problemas, obstáculos y expectativas pesimistas dominantes en los estudios anteriores, lo que indica que CES BRICS no solo cuenta con el apoyo del gobierno chino, sino también con la aceptación de los participantes chinos, que constituirá una importante fuente de motivación para el desarrollo sostenible de CES BRICS.

Palabras clave: países BRICS; cooperación en educación superior; la Universidad de Red de BRICS; China 


\section{Introduction}

The term "BRICs" was coined by Jim O 'Neill (2011), chief economist at Goldman Sachs, in his 2001 article "The World Needs Better Economic BRICs" in reference to the four major emerging economies of Brazil, Russia, India and China. Given the rapid rise of these four countries and their growing global influence and driven by their common interests, the leaders of China, Brazil, Russia and India held the first official BRICs meeting in 2009, officially launching multilateral cooperation among the BRICs countries. In 2011, South Africa became a new member of the group, now known as BRICS. Since then, BRICS cooperation has gradually evolved from a single-level foreign minister meeting to a multilevel cooperation covering different areas and issues, with a summit meeting as the centerpiece. It has gradually expanded from economic and political cooperation to cultural exchanges and educational, scientific and technological cooperation. In November 2013, the first BRICS Education Ministers' Meeting was held at the 37th UNESCO General Conference in Paris, starting the process of multilateral education cooperation among the BRICS countries, of which higher education cooperation is a key element and priority area. Currently, two major multilateral cooperation platforms, the BRICS Network University (BRICS NU) and the BRICS University League, exist, and a series of collaborations in research and talent training have been carried out.

BRICS higher education cooperation (BRICS HEC) is defined in this study primarily as multilateral cooperation in higher education among BRICS countries. As BRICS HEC has advanced, research interest in this topic has also increased. At present, researchers have pointed out significance and benefits of higher education cooperation among BRICS countries, such as helping promote cultural exchange among BRICS countries (Muhr and Luiz, 2018; Kovalev and Shcherbakova, 2019), building a new model of higher education cooperation (Khomyakov, Dwyer and Weller, 2020; Muhr et ál., 2018; Li, 2018), increasing the voice of developing countries in global higher education (Khomyakov, 2018), and helping developing countries jointly tackle the challenges of the internationalization and commercialization of higher education (Singh, 2017). On the other hand, in view of the historical, political, social and economic differences between BRICS countries, Altbach and Bassett (2014ab) argued that it makes little sense to lump them together for analytical purposes in higher education research and that the study of BRICS countries does not shed light on the higher education experience of other emerging economies.

In terms of cooperation progress, some researchers have pointed out that BRICS countries have achieved many notable results in higher education cooperation. For example, the number of international students in China from BRICS countries has been steadily increasing (Cheng, 2020), and the number of papers coauthored by researchers from BRICS countries has been on the rise each year (Wang, Liu and Sun, 2018). Accordingly, some researchers have positive expectations for the future development of BRICS HEC. They believe that BRICS HEC "faces unprecedented development opportunities" (Li, 2018, p. 393) and that "the scale and output of scientific research cooperation among the five countries will maintain the trend of rapid growth in the future" (Liu, 2015, p. 73-74). On the other hand, many more researchers have pointed out that higher education cooperation among BRICS countries has encountered many problems and obstacles; for example, students and scholars from BRICS countries prefer Western developed countries over other BRICS countries for studying abroad and exchange (Rensburg, Motala and Arulraj, 2015; Rensburg, Motala and Arulraj, 2016). Some planned cooperation 
projects have not been implemented, and cooperation still suffers from poor communication, slow progress, and a decision-making process that is too complicated (Varghese, 2015; Kovalev et ál., 2019; Khomyakov, 2018). Accordingly, some researchers have made more negative evaluations of the progress of cooperation, arguing that cooperation in higher education among BRICS countries is still "limited" (Rensburg et ál., 2016, p. 357), "weak" (Finardi and Buratti, 2016, p. 445), and not "intensive" (Khomyakov, 2018, p.340). Researchers also have relatively low and even pessimistic expectations for the future development of BRICS HEC (Oleksiyenko and Yang, 2015, p. 6).

Obviously, scholars hold different views and judgments on the significance, progress and prospects of BRICS HEC; some of them are positive and optimistic, and some are negative and pessimistic. The views of Chinese researchers seem to be more positive and optimistic than those of non-Chinese researchers. What are the views and evaluations of those involved in BRICS HEC? This question cannot yet be answered due to a lack of relevant empirical research. Given China's importance among the BRICS countries and the convenient access to "insiders" such as Chinese researchers and participants, this study aims to determine the views and judgments of participants from Chinese universities regarding the significance, progress and prospects of multilateral cooperation in higher education among BRICS countries.

As we already know, the Chinese government attaches great importance to cooperation among BRICS countries. This can be seen from the various policies issued by the Chinese government, such as the "Opinions of the Ministry of Education and Eight Other Departments on Accelerating and Expanding the Opening-Up of Education in the New Era" (2020) and the declarations resulting from previous meetings of leaders. What we do not know yet is what the people carrying out the cooperation projects think of the significance of BRICS HEC. How do they evaluate the progress of their cooperation efforts? What are their expectations and judgments about the future of BRICS HEC? Answers to these questions will indicate whether BRICS cooperation can be successfully implemented at the university level and achieve sustainable development. Therefore, knowing their views and judgments is of great value for evaluating the current situation and future development of BRICS HEC.

To this end, six Chinese experts who are involved in organizing or/and researching BRICS HEC in Chinese universities were interviewed about their views and judgments on the significance, progress and prospects of that cooperation. In the following, we first briefly review the emergence and development of BRICS HEC (section 2), then present the methodology (section 3) and findings (section 4) of this study, and finally, conclude with a discussion and conclusion (section 5).

\section{Emergence and development of BRICS higher education cooperation}

The cooperation initiatives of the BRICS countries began with economic cooperation and have now expanded to the political security, social and cultural fields. Cultural exchanges and cooperation have gradually become the third pillar of BRICS cooperation after economic development and political security. In the first Joint Statement of the BRICS Countries' Leaders in 2009, it was stated that "we reaffirm to advance cooperation among our countries in science and education with the aim, inter alia, to engage in fundamental 
research and development of advanced technologies (University of Toronto, 2009).” The Sanya Declaration of the Third BRICS Leaders' Meeting in 2011 mentioned the establishment a "BRICS-UNESCO GROUP" within UNESCO to develop "common strategies within the mandate of the Organization (University of Toronto, 2011)." In this context, the first BRICS Education Ministers' Meeting was held in Paris as part of the 37th session of the UNESCO General Conference, which initiated the process of the institutionalization of multilateral cooperation in education among the BRICS countries, including the field of higher education. Therefore, although bilateral cooperation in higher education among the five BRICS countries existed before the establishment of the BRICS cooperation mechanism, multilateral cooperation among the five countries began in 2013.

From 2013 to 2020, the BRICS countries held seven BRICS Leaders' Meetings and BRICS Education Ministers' Meetings. After each meeting, initiatives and goals for BRICS higher education cooperation were put forward, including the following: establishing the BRICS Network University (BRICS NU) and the BRICS University League; developing common principles of qualification and quality assurance; establishing a network of research and education centers of excellence prioritizing the main areas of collaboration among the leading universities of the BRICS countries; supporting joint research projects; encouraging more collaborative programs at the postgraduate, doctorate and postdoctorate levels; promoting the joint-publishing of scientific results by BRICS universities; promoting structural dialogue and the exchange of best practices among BRICS universities; facilitating the mobility of students; expanding the number of scholarships and encouraging the exchange of faculty members, especially those working in the areas relating to six domains identified for cooperation within the BRICS NU; developing an enabling framework to promote research cooperation and knowledge transfer among BRICS countries in collaboration with other BRICS initiatives, such as the BRICS think tanks; and organizing "summer/winter school" to build a platform for exchange and cooperation among new generations(University of Toronto, 2020 $\square$ BRICS Network University, 2018).

The BRICS NU and the BRICS University League are two important BRICS HEC projects through which cooperation programs are developed and resources are integrated to provide platforms for substantive cooperation among BRICS universities. Here is a brief introduction to these two projects.

The BRICS NU was established in accordance with the Memorandum of Understanding on the Establishment of the BRICS NU signed at the Third Meeting of the BRICS Education Ministers in 2015. It is "a network of the BRICS member countries' higher education institutions engaged in cooperation and joining the BRICS NU” and "an educational project aimed at developing, preferentially, bilateral/multilateral shortterm joint training, master's and $\mathrm{PhD}$ programmes along with joint research projects in various knowledge fields according to common standards and quality criteria, given recognition of learning outcomes by BRICS NU participants as per national criteria(BRICS Network University, 2015)". This project aims to create a unified educational environment, enhancing the academic mobility and training of highly qualified professionals in the top priority areas of the member states' development (Smagina, 2016).

At present, 56 universities have joined BRICS NU, 9 from Brazil, 11 from China, 12 from India, 12 from Russia and 12 from South Africa. There are six priority areas for cooperation between universities ("knowledge field priorities"), including energy, computer science and information security, BRICS studies, ecology and climate change, 
water resources and pollution treatment, and economics. The BRICS NU has three levels of regulatory bodies: the BRICS NU International Governing Board (IGB) is the principal integral body and is responsible for activities and development, the BRICS NU National Coordination Committee (NCC) oversees the operations and management of the BRICS NU at the national level, and the BRICS NU International Thematic Groups (ITG) provide support for the BRICS NU's educational activity according to the identified knowledge field priorities (BRICS network university, 2015).

At the meeting of the IGB of the BRICS NU in October 2020 four development stages were set, including the preparatory stage (2015-2020), formation stage (2020-2022), approbation and implementation stage (2023-2025) and stage at which the institution will become fully operational (beginning in 2026) (BRICS RUSSIA 2020, 2020). As of now, the BRICS NU has just completed the preparatory stage.

The BRICS University League was established according to the BRICS University Presidents' Forum Beijing Consensus, which was signed at the forum held at the Beijing Normal University in China in 2015. The first plenary session of the BRICS University League was held in Shanghai in May 2019, and the participants discussed the league's regulations, governance structure, student exchanges and joint training, teacher exchanges, research cooperation and so on. The BRICS University League is mainly promoted by Beijing Normal University and Fudan University (Shanghai). The league is presented as an independent organization comprised of universities (Khomyakov, Panova, Piskulova, and Abramova, 2015). As the BRICS University League is more like a cooperation forum, it is not as binding as the relatively institutionalized BRICS NU.

The two cooperative projects could be integrated in the future. The Declaration of the 12th BRICS Summit held in Moscow in December 2020 stated that "we encourage consolidation of the BRICS Network University and BRICS University League so as to provide synergetic engagement of their activities (Xinhua Net, 2020).”

The conditions created by these two cooperation platforms have facilitated a series of multilateral cooperation activities among the BRICS countries. For example, the BRICS Summer School Program organized by the Center for BRICS Studies of Fudan University, which is "the first program in BRICS education cooperation" and has been held for seven consecutive years since 2014, aims to create a platform for consensus and friendship among young students from BRICS countries (BRICS Business Council, 2020). In 2017, the Ural Federal University of Russia hosted the "BRICS Future 2030" Spring International Workshop, which explored topics related to politics, the economy, education, the humanities and urban development in BRICS countries. It attracted graduate students and young researchers from BRICS countries and other countries (BRICS Network University, 2017).

In addition to multilateral cooperation projects, the BRICS countries have also developed bilateral collaboration under the new multilateral cooperation framework, a representative example of which is the "Ural Institute of North China University of Water Resources and Electric Power", organized in cooperation with the Ural Federal University of Russia. It was established in 2017 and is the first jointly organized higher education institution established under the framework of BRICS HEC in China (Henan Education Association for International Exchange, 2018). 


\section{Methodology}

The purpose of this study is to determine the views and judgments of Chinese university participants regarding the significance, progress and prospects of BRICS HEC. We have chosen to focus on the significance, progress and prospects of BRICS HEC because they are the three core dimensions for describing and assessing BRICS HEC, reflecting the logic of its emergence and development as a new cooperation project.

To allow interviewees to fully articulate their views and reasoning in response to our questions, semi-structured interviews were used in this study. To ensure that the interviewees had relevant knowledge, they not only were members of Chinese universities that are involved in BRICS HEC but also had a thorough understanding of BRICS HEC. This means that the interviewees in this study were "experts" in this field who were familiar with practices in this field and, at the same time, had relevant reflective knowledge. Therefore, in terms of the interviewees, this study had "expert interviews" (Flick, 2009, p.165).

The choice of using expert interviews is based on the advantages of this research method, which is viewed as "a more efficient and concentrated method of generating data" than, for instance, participatory observation or systematic quantitative surveys, and "can serve to shorten time-consuming data-producing processes " (Bogner, Littig and Menz, 2018).

The sampling method adopted in this study was purposive sampling (Schreier, 2018); i.e., the participants were selected according to the requirements identified above. The subjects who met the requirements of this study were mainly those in charge of exchange and cooperation affairs with other BRICS countries in Chinese universities (e.g., leaders of international exchange and cooperation offices, heads of cooperation projects) and researchers studying higher education cooperation among BRICS countries.

During the process of finding experts to be interviewed, we encountered two major difficulties. First, there are very few relevant research experts in China. Although there are some experts who study higher education in BRICS countries, very few of them study cooperation in higher education among BRICS countries. We contacted three experts by email, and through a referral from an acquaintance, and we interviewed two of them. Second, the participation rate of leaders of international exchange and cooperation offices was low. Using email and phone, we contacted the heads of the International Exchange and Cooperation Offices of 15 Chinese universities that are members of both the BRICS NU and the BRICS University League, and only two of them accepted our interview request. By explaining the reasons for not participating, some leaders of the International Exchange and Cooperation Office said that they had many things to do during the period of our investigation and could not find time for interviews or that they could not provide the required information because their universities were not very involved in relevant collaborations. In addition, we contacted three Chinese coordinators of the BRICS NU International Thematic Groups by email, and one of them accepted our interview request. Following a recommendation by an acquaintance, we also interviewed one of the leaders of a BRICS NU Cooperation Project. As a result, six experts from four Chinese universities were interviewed (see Table 1). 
Table 1.

Information about experts interviewed

\begin{tabular}{lll}
\hline Interviewed Experts & Gender & Job Information \\
\hline Expert A & Female & Head of International Exchange and Cooperation Office \\
\hline Expert B & Male & Head of a BRICS NU Cooperation Project \\
\hline Expert C & Male & Researcher at a BRICS Cooperation Center \\
\hline Expert D & Female & Researcher at a Center for BRICS Studies \\
\hline Expert E & Male & $\begin{array}{l}\text { Coordinator of the BRICS NU International Thematic } \\
\text { Groups }\end{array}$ \\
\hline Expert F & Female & Head of International Exchange and Cooperation Office \\
\hline
\end{tabular}

The interviewees all met our abovementioned criteria and were involved in organizing or/and researching BRICS HEC in Chinese universities. The two researchers interviewed were also actively involved in the organization and implementation of the cooperation projects within the framework of BRICS NU and University League. Because the studied group is very small, further information about the individual interviewees may reveal their identity, so we refrain from revealing more information here.

When we contacted the interviewees, we provided an outline of our interview. In addition to an introduction to our research, a statement attesting to our confidentiality commitment, informed consent and other information, the interview outline mainly included the following questions: (1) Do you think it is necessary for BRICS countries to cooperate in higher education? If so, what is the significance of the collaboration? (2) In terms of areas you are familiar with, what major achievements have been made in BRICS HEC? What are the main problems? (3) If you were asked to rate the current situation of BRICS HEC on a scale of 0-100, how would you rate it? What is the reason for your rating? (4) Some people think that the cooperation of BRICS countries lacks "mortar" (that there is a lack of cohesion) due to differences and conflicts of interest among the countries. Some believe that BRICS HEC is of little significance. What is your opinion on this? (5) Where do you see the future development of BRICS HEC going?

All interviews were conducted online (via Tencent Meeting) between December $5^{\text {th }}$, 2020 and January 29th, 2021. The interviews lasted between 40 and 90 minutes. All interviews were recorded with the consent of the interviewees. The recordings were completely transcribed into text. The transcription followed the principles of standard orthography proposed by Kowal and O'Connell (2014), which focuses on the content rather than the form of expression (e.g., dialect, intonation, silence, etc.). The language of the interviews was Chinese, and the quotes in the findings section are translations.

NVivo 12 was used to code and analyze the interview text. The coding and analysis were carried out according to the method of thematic qualitative text analysis proposed by Kuckartz (2014), and three main thematic categories were identified, namely, the necessity and significance of cooperation, the progress of cooperation, and future perspectives. Parts of the text (the ratings and prospects sections) were analyzed using evaluative qualitative text analysis (Kuckartz, 2014). The coding was performed by both authors using the consensual coding approach (Kuckartz, 2014), whereby the two authors independently coded with the same coding frame, then compared the similarities and differences, and finally, reached a consensus on the coding through discussion. In addition, word frequency analysis was conducted using NVivo 12. 


\section{Results}

The six interviewed experts' views and judgments on the significance, progress and prospects of BRICS HEC are presented here.

\subsection{Significance of BRICS higher education cooperation}

All six experts interviewed recognized the need for cooperation in higher education among the BRICS countries. For example, expert F said that the BRICS HEC "is not only necessary, but also a must, and urgently needed at the moment". In response to the question, "What is the significance of higher education cooperation among BRICS countries", the experts mentioned various areas of significance covering four levels. At the individual level, cooperation provides more international exchange opportunities for students and teachers. At the institutional level, by complementing each other's strengths, cooperation contributes to the fulfilment of the three core functions of higher education institutions (teaching, research and social services) and helps promote the internationalization of higher education institutions and enhance their international competitiveness. At the national level, cooperation is regarded as an important supplement to the country's public diplomacy, helping promote cultural exchanges and people-to-people bonds among BRICS countries. At the supranational level, higher education cooperation among the BRICS countries helps enhance the voice of the five countries in global educational governance and create a model of higher education cooperation among developing countries that is different from the model of cooperation with Western developed countries.

Among the various areas of significance mentioned above, the following three areas are most discussed by experts.

The first area is the significance of BRICS HEC for talent training. All six experts mentioned that BRICS HEC can provide more opportunities for students to study and do exchanges abroad through degree or nondegree programs such as summer schools, winter schools and other short-term cooperation programs. Those activities can "provide a source of good students" (expert E) for international degree programs of universities, expand "students' international horizons" (expert B), and "train the future leaders in science and technology for the five countries, as well as the future elites in politics and business" (expert C). Alluding to the popular concept of the "second generation rich" in China, expert D used the term "second generation BRICS":

"What we cultivate through higher education activities are the second generation BRICS, namely, young people who will be useful for future BRICS cooperation and high-quality talents who will provide intellectual support not only for the development of the countries but also for the future cooperation of BRICS countries." (expert D)

The second area is the significance of BRICS HEC in promoting cultural exchange and people-to-people bonds among BRICS countries. Because the BRICS countries are culturally different, are geographically far apart, and have problems such as not knowing each other or even having prejudices against each other, the interviewed experts believe that BRICS HEC can increase mutual understanding, eliminate cultural prejudice and barriers, and enhance the willingness of teachers, students and others to communicate and reach a consensus. In this sense, BRICS HEC has an important mission to promote cooperation among the BRICS countries as a whole and is therefore "very significant 
and indispensable, especially from the perspective of people-to-people bonds and cultural exchanges" (expert A).

Finally, there is the significance of BRICS HEC in enhancing the voice as well as the influence of the five countries in global educational governance. As emerging economies, the BRICS countries are confronted with the reality that the developed countries of Europe and North America are still the leading group, which means that the power of any single country is insufficient to change the existing rules and order of higher education, so it is necessary to cooperate. As expert $\mathrm{C}$ said:

"The fact is, up to today, the high ground or the leading group in global higher education is still in the developed countries of Europe and North America, and perhaps this means for these five transition countries or emerging economies, if they want to truly join and lead the reform of global higher education rules, the five countries must still really cooperate and huddle together; otherwise, I think it is very difficult." (expert C)

In addition, BRICS HEC helps create a "model of higher education cooperation in developing countries" (expert A) that is different from the model of cooperation with Western developed countries. Its core feature is that all parties involved have an equal status, rather than some being advanced and some lagging behind, and that all parties are willing to move towards each other rather than forcing some to move towards others. This kind of cooperation can contribute to the democratization of the global educational order rather than to the maintenance of the dominant position of developed countries in Europe and North America, so it provides "a better model of educational cooperation for some emerging economies or South-South cooperation.” (expert D)

\subsection{Progress of BRICS higher education cooperation}

How the interviewed experts evaluate the progress of BRICS HEC is presented here in terms of achievements, problems and ratings.

\subsubsection{Achievements}

When asked what achievements have been made in the BRICS HEC, the six experts all mentioned that the main achievements are the successful establishment of the two platforms for cooperation, namely, the BRICS NU and the BRICS University League. These two multilateral cooperation platforms "have played a significant role in attracting more and more higher education institutions from BRICS countries to join the alliance," expert A said. According to the interviewees, there are clear differences between the two platforms.

First, the initiators and leaders of the two platforms are different. The BRICS NU was initiated by the Russian side and led by the Ural Federal University. It is "a more Russian-led cooperation mechanism" (expert D). The BRICS Universities League was initiated by the Chinese side: "It is led by us, led by the Chinese side" (expert E).

Second, their operating mechanisms and degrees of institutionalization are different. The BRICS NU is "an institutionalized organization; it has thematic groups and boards, such as the governing board and the committees of working groups, so it is more organized" (expert E). The BRICS University League, on the other hand, is "less institutionalized" and "feels like a forum, [that is] not particularly binding" (expert E). 
Finally, the nature of the two is different. The BRICS NU is promoted by the ministries of education and has an official character. The BRICS University League, on the other hand, is an activity initiated and organized by universities and is "purely initiated by the people" (expert A). Although it has also received strong support from governments, the league is a nongovernmental activity by nature.

Under the framework of these two cooperation projects, BRICS higher education cooperation has achieved much in terms of research and talent training. The achievements in research cooperation mentioned by the interviewees include mutual visits between scientists, conferences and forums, joint research projects, and the joint publication of results in international journals. The interviewees did not provide relevant figures here but cited a number of collaborative projects and cases. For example, expert E said:

"We have used this working group meeting to implement cooperation with international journals, such as SSCI journals, and cooperate with them to run a Special Issue on the subject of the BRICS. This was the goal of the work set at the XXX working group meeting in 2018, and now this project is almost complete... This is one of the fruitful results." (expert E)

In terms of talent training, the interviewed experts mentioned the following achievements: joint programs such as double-degree programs and joint training with dual $\mathrm{PhD}$ supervisors, short-term and long-term student exchange programs, and summer schools, summer camps and winter camps. According to the interviewees, the BRICS countries have "made considerable progress" in promoting short-term student exchange programs (expert C), and there has been "a significant increase" in the number of students moving across borders within BRICS countries (expert A). Expert C concluded that

"It has basically achieved the goal of BRICS countries to promote exchanges among young generations through cooperation and the consolidation of the friendship of future generations in the BRICS countries." (expert C)

\subsubsection{Problems}

The interviewees also mentioned a series of problems, the most prominent among which are the following:

First, BRICS HEC faces difficulties in achieving multilateral cooperation, i.e., there are "more bilateral collaborations, but less cooperation among five countries together" (expert D).

Second, there are difficulties regarding the mutual recognition of credits and qualifications in BRICS HEC at present. Although this is one of main goals of such cooperation, the interviewees generally believe that there have been no breakthroughs in this regard because it involves "the issue of national educational sovereignty":

"Because each country has its own unique system of education diplomas, or diplomas that it recognizes, it is impossible to achieve this kind of joint training program among five countries, saying that we do a joint training program, studying in each of the five countries for one semester, and then each country recognizes his diploma. It cannot be done-it can't be achieved at present." (expert A). 
Third, some actors are less motivated to cooperate with BRICS countries. One interviewee stated that "Chinese universities are actually not very active and enthusiastic about participating in real BRICS HEC" (expert C) because Chinese universities are more interested in cooperating with Western developed countries. However, he also pointed out the exceptions:

"Of course, Beijing Normal University is very active...Fudan University is very active....another one is North China University of Water Resources and Electric Power; it is very active and highly enthusiastic about this cooperation." (expert C).

For Chinese students who are planning to study abroad and their parents, the preferred destinations are still Europe and North America, and those who want to study in BRICS countries "are relatively few, or at least [it is] not a priority of the majority of students" (expert D). University faculty also tend to give preference to working with faculty from universities in Europe and North America. Talking about the reasons for this phenomenon, expert A said:

"On the one hand, the global center of technology and education is still the Western developed countries. On the other hand, it's because of the lack of understanding [among people in the BRICS countries]. As I mentioned earlier, our teachers, students, parents and enterprises may think that they won't feel safe in Brazil, the public security is not good; India is very terrible, living there they will be in fear of their lives every day. So, it constrains their horizons, restricts their choice, lowers their willingness, and makes the participants' will regarding this less strong." (expert D)

In terms of enthusiasm for participating, there are also differences among the five BRICS countries, according to the statements of the interviewed experts. The word frequency analysis performed by NVivo 12 shows that the BRICS countries were mentioned in the interviews with the following frequencies: China 227 times, Russia 157 times, Brazil 87 times, India 86 times and South Africa 63 times. This also reflects the importance and influence of BRICS countries in higher education cooperation. Obviously, in the eyes of the Chinese experts interviewed, the roles played by China and Russia are more prominent, while the roles played by Brazil, India and South Africa are relatively inferior.

Finally, four of the experts interviewed mentioned the difficulty in implementing good cooperation plans and ideas. As expert B said,

"At the moment, it's more likely that there are more initiatives or ideas, but not so many of them are actually put into practice." (expert B).

\subsubsection{Ratings}

After discussing the achievements of and problems with cooperation, we asked each of the interviewed experts to rate the progress of BRICS HEC on a scale of o-100 points. Except for one expert who gave a "failing" grade (below 60), the remaining five experts gave different levels of positive evaluations, ranging from passing to good (and even partially excellent). The experts' scores and their reasons are shown in Table 2. 
Table 2.

Interviewed experts' evaluation of BRICS HEC. "How would you rate the current situation of BRICS HEC on a scale of $\mathrm{o}-100$ ?”

\begin{tabular}{|c|c|c|}
\hline Experts & Scores & What are the reasons? \\
\hline \multirow[t]{2}{*}{ Expert A } & $\begin{array}{l}\text { "I would } \\
\text { probably } \\
\text { score it as } \\
50 "\end{array}$ & $\begin{array}{l}\text { "At the moment, this kind of linked system and mechanism of BRICS HEC has } \\
\text { actually not been formed. We are all still exploring what we can actually do } \\
\text { together, and then what we can't touch, what we can't do....For good higher ed- } \\
\text { ucation cooperation, it is still necessary to form a stable, mutually agreed-up- } \\
\text { on and established mechanism first. Only on the basis of this mechanism can } \\
\text { more significant results be achieved. So, there is still a lot of room for improve- } \\
\text { ment." }\end{array}$ \\
\hline & & $\begin{array}{l}\text { "After all, it has also been going for only a limited period of time and its foun- } \\
\text { dation is much weaker than the foundation on which we carry out bilateral } \\
\text { cooperation, so I think it is already not easy for BRICS HEC to reach } 50 \text { points } \\
\text { even today." }\end{array}$ \\
\hline Expert B & $\begin{array}{l}\text { "I give it } 60 \\
\text { points-a } \\
\text { pass". }\end{array}$ & $\begin{array}{l}\text { "Although there are already applied projects, established institutions, collab- } \\
\text { orative research and exchanges between teachers and students that have been } \\
\text { carried out, as I mentioned earlier, we have not yet achieved very encouraging } \\
\text { results in terms of breadth and depth,...Because it is international cooperation, } \\
\text { is also very difficult and affected by the international political and economic } \\
\text { situation as well as cultural and other aspects. This road will be very difficult } \\
\text { and long, but it has been launched, and this is still a good thing." }\end{array}$ \\
\hline Expert F & $\begin{array}{l}\text { "About } 65 \\
\text { points, at } \\
\text { most } 70 \\
\text { points" }\end{array}$ & $\begin{array}{l}\text { "I think it is about } 65 \text { points, at most } 70 \text { points. That is to say, a score of } 70 \\
\text { points is to show its significance. It is not yet so intensive, so systematic, nor } \\
\text { has it reached such a high level as the cooperation with the US and other West- } \\
\text { ern countries. But it is of great importance. It covers a large range of popula- } \\
\text { tion and includes important economies." }\end{array}$ \\
\hline Expert C & $\begin{array}{l}\text { "I would } \\
\text { probably } \\
\text { score } 70 \\
\text { plus } 5 \text { ". }\end{array}$ & $\begin{array}{l}\text { "Because these five countries have a very high expectations for BRICS coopera- } \\
\text { tion, the expectations for education cooperation are also very high. But instead } \\
\text { there is no obvious achievements, so this may be why it is scored a little lower } \\
\text { at } 70 \text { points. But there is a plus } 5 \text { to take into account the fact that the founda- } \\
\text { tion of the cooperation is really weak, [and] the historical starting point is rel- } \\
\text { atively low. In such a difficult situation some progress can still be made, which } \\
\text { is not easy, so the } 5 \text { points are a sympathy score, an encouragement score, } 70 \\
+5 . "\end{array}$ \\
\hline Expert D & $\begin{array}{l}\text { "It's almost } \\
\text { at a good } \\
\text { level". }\end{array}$ & $\begin{array}{l}\text { "We still have some pragmatic cooperation in higher education every year, } \\
\text { including the ministerial meeting. And in the declarations, the cooperation in } \\
\text { higher education is also highlighted every year. It's still a little bit away from } \\
\text { being excellent, because there are still some shortcomings and difficulties, as } \\
\text { mentioned before, so I think it's almost at a good level." }\end{array}$ \\
\hline Expert E & $\begin{array}{l}\text { "About } 80 \\
\text { points". }\end{array}$ & $\begin{array}{l}\text { "Now, looking at the overall situation, I think the level of cooperation in higher } \\
\text { education among the BRICS countries should be satisfactory, about } 80 \text { points. } \\
\text { If it's like the XXX working group, the cooperation in our group is relatively } \\
\text { advanced in several major areas, we should be able to get 9o points." }\end{array}$ \\
\hline
\end{tabular}

Judging from the reasons given by the interviewees, their evaluations of higher education cooperation among BRICS countries all take into account the initial conditions of the cooperation, such as its short period of existence thus far, its weak foundation for cooperation and other difficulties it has faced, so five of them still evaluate it positively despite seeing these problems.

\subsection{Prospects for BRICS higher education cooperation}

When asked about the future development of BRICS HEC, five experts are optimistic, and one is pessimistic. The expert who is pessimistic about the future development of this cooperation is the same expert who gave a "failing grade" to its progress thus far. 
She said, "At the moment, in terms of education, there may not be a breakthrough in the near future" (expert A). She reasoned that the coronavirus epidemic and changes in international relations (e.g., the deterioration of Sino-Indian relations), coupled with the slowdown in economic growth in some BRICS countries (Russia, Brazil, and South Africa) that was already occurring, have "weakened" the "basis of existence" of the BRICS association, which is primarily based on economic ties. This "will have a relatively large impact on BRICS cooperation" (expert A).

The expert who gave a "passing grade" to the BRICS higher education cooperation expressed that although he could not say he was "very optimistic", he was certainly not "completely pessimistic" about the future development of BRICS HEC because "we will continue to move forward along the BRICS education cooperation path" (expert B).

Unlike the above two experts, the other four experts are "more optimistic" (expert E) or even "very positive"(expert F) and "very optimistic" (expert D) about the future development of BRICS HEC. For example, expert D said:

"I think its future development still has great potential, and I am very optimistic. This year, it is so difficult for us because of the coronavirus epidemic, but even in such a difficult situation, the BRICS summit was still held, our summer school was also held, and the BRICS Education Ministers' Meeting was also held. This indicates that future BRICS cooperation will continue to develop in the direction of pragmatic cooperation, and this is also the case for our higher education [cooperation]. So, I am quite optimistic about the future development of higher education [cooperation].” (expert D)

In the interviews, the interviewed experts also explained the reasons for their optimism. First, in the current global governance structure, BRICS countries can gain a voice and influence and push for changes in relevant international rules only by uniting, cooperating and "huddling together for warmth" (expert C). Second, the governments of BRICS countries attach great importance to cooperation among their countries and share a common will to promote cooperation in higher education. Third, the BRICS countries all have "ambitious" plans for higher education development and want to make their own higher education excellent, i.e., they share the same development vision. Fourth, BRICS countries have similar levels of development and face some common problems, so they have more common experiences. Fifth, there is no conflict among the BRICS countries in terms of political systems and ideologies, in contrast to the resistance of European and North American countries towards China. In view of this, expert C said that BRICS countries have "many opportunities for cooperation" and "many areas of cooperation" and that "the prospects are very broad".

\section{Discussion and conclusion}

BRICS HEC was initiated from the top by the BRICS governments. The governments' promotion of and support for BRICS HEC are certainly important for the successful development of such cooperation. However, if the collaboration and sustainable development goals are to be achieved, the acceptance and support of universities, teachers and students will be indispensable. In this sense, knowing the views of the participants is of vital importance for evaluating the progress and future development of cooperation. 
Through interviews, this study found that the six interviewed experts clearly recognized the necessity of higher education cooperation among BRICS countries and believed that it has the following significant benefits: providing students and teachers with more opportunities for international exchange and cooperation, improving the internationalization and international competitiveness of universities, promoting cultural exchanges and people-to-people bonds among the BRICS countries, enhancing the voice of the BRICS countries in global educational governance, and creating a higher education cooperation model that is different from the cooperation model involving Western developed countries and is more applicable to developing countries.

The areas of significance of the collaboration found in this study are consistent with those identified by existing studies. For example, researchers have pointed out that BRICS countries oppose the narrow view of human capitalists and reassert the noneconomic role of education in development, which is underscored by the overall BRICS education cooperation objective of fostering "cultural exchanges" via "people to people exchanges" (Muhr et ál., 2018, p.528). Higher education cooperation creates "useful platforms for establishing a dialogue between education specialists, facilitating closer scientific and educational contacts between member countries, and expanding the possibilities for BRICS to develop in the areas of information and education for common exchange" (Kovalev et ál., 2019, p.540). BRICS HEC may establish an "alternative model of university cooperation and higher education development” (Khomyakov, 2018, p.339). BRICS HEC has shared the "BRICS Solution" with the world, and the valuable practical experiences gained can be applied to the development of higher education in the Global South ( $\mathrm{Li}, 2018$, p.403). In fact, except for the negative view of Altbach et ál. (2014) mentioned in the introduction, the majority of researchers have affirmed the significance and necessity of higher education cooperation among BRICS countries.

In terms of the progress of BRICS HEC, this study found that the main achievements from the perspective of the interviewed experts have been the establishment of the two platforms for higher education cooperation, namely, BRICS NU and BRICS University League, and collaboration in research (such as academic visits and conferences, collaborative research and joint publications) and talent training (such as joint education programs and short-term exchange projects). The interviewed experts did not provide specific figures in the interviews. However, existing studies have provided data to support their views. For example, Chen Jing's (2020) research found that the number of international students from BRICS countries studying in China doubled between 2010 and 2018, growing from 22,641 to 46,881 . The growth rate of this figure is slightly faster than that of the total number of international students coming to China. In addition, the number of international students from BRICS countries in China who have received Chinese government scholarships has also been increasing, and the proportion of scholarship recipients among international students from BRICS countries studying in China has increased from $5.3 \%$ to $9.6 \%$. Through an analysis of articles included in the database of Science Citation Index Expanded (SCI-EXPANDED) and Social Science Citation Index (SSCI), researchers found that since the establishment of BRICS, the number of articles published by BRICS researchers in bilateral or multilateral cooperation has increased from 1,801 in 2010 to 5,112 in 2016 (Wang, et ál., 2018). This reflects the increase in collaboration among researchers in BRICS countries.

The current cooperation problems identified by this study mainly involve the difficulties in achieving multilateral cooperation and mutual recognition of credits and academic 
qualifications, the lack of enthusiasm among relevant potential participants, and difficulty of implementing good plans and ideas. Despite these problems, when evaluating the progress of BRICS higher education cooperation, all of the other experts except for one expert who gave it a "failing grade" gave positive evaluations to varying degrees. Similarly, all experts were optimistic about the future development of BRICS HEC except for the expert who gave the "failing grade", whose outlook was rather pessimistic.

The findings of this study differ somewhat from the pictures presented by existing studies. The interviewees in this study all clearly recognized the significance and necessity of BRICS HEC. Although they saw problems, most of them felt positively about the development of such cooperation to date and its future prospects. Their views are obviously optimistic. In contrast, the image depicted by most existing studies are more negative and pessimistic because they primarily emphasize problems and obstacles; for example, the preferred destinations of students from BRICS countries are not other BRICS countries (Rensburg et ál., 2015). The proportion of collaborative research among BRICS researchers is still very low because researchers from other BRICS countries are not their preferred collaborators (Rensburg et ál., 2016). Collaboration among BRICS countries is rather limited and still in the nascent stages. Cooperation and collaboration in higher education is more common between BRICS and developed countries (Varghese, 2015). There is bureaucratic complexity in the project as well as a lack of a clear understanding of how to attract students to the new programs, and this has slowed down the progress of such collaboration (Kovalev et ál., 2019). In many respects, educational collaboration among BRICS countries is still very much in the planning stage rather than a reality, and collaboration in research and education among BRICS countries has never been very intensive (Khomyakov, 2018).

In terms of the future prospects for BRICS HEC, other scholars' judgments, especially those of non-Chinese scholars, are also not optimistic. For example, Oleksiyenko et ál. (2015) pointed out that because of the different aspirations and capacities for global outreach,
"the five BRICS countries can hardly claim that they can make a paradigm shift in the conceptualization of international higher education partnerships as a transcontinental multinational bloc. The vision and creativity necessary for the conceptualization of global roles, as well as institutional leadership for advancing these roles, are weak. In that regard, no revolutionary changes that would propel BRICS as a global pacesetter can be foreseen" (p.5-6).

Although some researchers have cautioned that BRICS HEC has just started and that it is still too early to evaluate it (Rensburg et ál., 2016 $\square$ Khomyakov $\square$ 2018), people seem unable to avoid evaluating it-be it positively or negatively. We think that it is necessary to review and evaluate the development of BRICS HEC to improve the relevant practices. The question is not when the evaluation should be done but what perspective should be taken and what criteria should be used. The question of what makes for reasonable evaluation perspective and criteria needs to be answered through research with a specific focus. Here we make some suggestions in this regard.

First, in the existing studies, researchers tend to compare the cooperation among BRICS countries with their cooperation with Western developed countries and thus come to the conclusion that the cooperation among BRIC countries is not close or intensive. 
The problem is that using Western developed countries as a standard for comparison is unfair because the cooperation between the BRICS countries and Western developed countries has a longer history and better foundation. Multilateral cooperation in higher education among BRICS countries has been in place for just seven years. The initial foundation was weak, and such cooperation has also faced additional obstacles. Therefore, a reasonable comparison would be a vertical historical comparison, i.e., comparing the current situation of the BRICS countries with the situation before the BRICS cooperation mechanism was established. Even if it is necessary to carry out a horizontal comparison, a comparison with similar developing countries is more reasonable than a comparison with Western developed countries in Europe and North America.

Second, the judgment of whether such cooperation is progressing well is actually determined by the evaluators' perspective and criteria used for the evaluation. Therefore, when faced with the same problem, evaluators with different perspectives and criteria may come to different conclusions. As far as the evaluation criteria are concerned, since BRICS HEC is a new model of higher education cooperation, it is necessary to explore new suitable evaluation criteria instead of simply adopting the existing evaluation criteria that are obviously dominated by and are more favorable towards Western developed countries (e.g., university rankings, global competitiveness rankings, SCI/SSCI, etc.). Since BRICS countries intend to break Western monopolies, this should naturally also include their monopoly on the evaluation criteria used in higher education development.

We suggest that the evaluation of BRICS HEC should be based on the goals set by the BRICS Leaders' Meeting and the Education Ministers' Meeting. For example, the promotion of cultural exchange and people-to-people bonds is an important goal of BRICS HEC. The realization of this goal requires both long-term efforts to reveal its effects and special measurement indicators. In addition, the evaluation needs to take into account the weak historical foundation and the many obstacles faced by multilateral cooperation among the BRICS countries.

Third, in terms of perspectives, when evaluating BRICS HEC, evaluators can either take a "detached" position and make an "objective and neutral" evaluation or take an "involved" position to support and defend the BRICS cooperation or to attack and question it on the basis of their country's own values and group interests (Schriewer, 1988). However, the position we appreciate most is constructive one aimed at improving practice because we think that as a new multilateral cooperation project, BRICS HEC deserves to be considered with goodwill, tolerance and patience. As the Chinese saying goes, "everything is difficult at the beginning"; what BRICS HEC needs most at this time is constructive comments, including well-intentioned criticism, rather than a negative chorus.

The optimistic views of the interviewees in this study and of the Chinese researchers cited in the introduction (e.g., Liu, 2015, and Li, 2018) can be attributed to the fact that they have already taken into account the three aspects suggested here, in addition to the reasons presented in section 4.3 of this paper, when evaluating the BRICS HEC. Additionally, their optimistic views may also be related to the overall optimism of Chinese society. Several public opinion surveys (e.g., YouGov, Pew Research Center, The Economist Intelligence Unit) in recent years have shown that Chinese people are among the most optimistic people in the world (Hernández and Bui, 2018).

The contribution of this study is that it provides the first interview-based insights into the views and judgments of Chinese participants regarding the significance, progress and prospects of BRICS HEC; furthermore, it finds that the Chinese participants are positive 
and optimistic in their views and judgments of such cooperation despite its problems, which is in contrast with the image of problems, obstacles and pessimistic expectations for future development that dominates previous studies. Given the important role China plays in the BRICS group, the views and judgments of Chinese participants have a crucial impact on the future development of BRICS HEC. This positive optimism embodied by Chinese participants indicates that higher education cooperation among BRICS countries is not only supported by the Chinese government but also accepted by the members of the participating universities. This constitutes an important driving force for the sustainable development of BRICS HEC in the future.

Due to the limited number of experts interviewed, the generalizability of the findings of this study is limited. Further insights into the views of Chinese participants could be obtained by expanding the range of interviewees or by supplementing them with other research methods (e.g., the content analysis of relevant online information). In addition, this study provides only one piece of the overall cognitive jigsaw puzzle that is higher education cooperation among BRICS countries. A similar study could be conducted for the other four BRICS countries in the future. By comparing the views of participants in the five countries, we could greatly expand our understanding of BRICS HEC and propose suggestions for further improvement accordingly.

\section{References}

Altbach, P. G. and Bassett, R. G.(2014a). Nix the BRICs-At Least for Higher Education Scholarship. Change: The Magazine of Higher Learning, 46(5), 30-33. doi: 10.1080/00091383.2014.941768

Altbach, P. G. and Bassett, R. G. (2014b). Nix the BRICs-At Least for the Higher Education Debate. International Higher Education, 77, 2-5. doi: 10.6017/ihe.2014.77.5671

Bogner, A., Littig, B., and Menz, W.(2018). Generating Qualitative Data with Experts and Elites. In U. Flick (Ed.). The SAGE Handbook of Qualitative Data Collection (653). London: Sage.

BRICS Network University (2015). Memorandum of understanding on establishment of the Brics Network University. Retrieved from http://nu-brics.ru/media/uploads/ filestorage/documents/MoU_SU_BRICS.pdf

BRICS Network University (2017). Different scenarios of the BRICS future were presented at Ural Federal University. Retrieved from http://nu-brics.ru/news/8/

BRICS Network University (2018). Important documents. Retrieved from http://nubrics.ru/pages/documents/

BRICS Business Council (2020). BRICS Summer Workshop (BRICS Program) 2020. Retrieved from http://www.brics-info.org/brics-summer-workshop-bricsprogram-2020/

BRICS RUSSIA 2020 (2020). Experts discuss Concept of functioning and development, as well as Roadmap for BRICS Network University. Retrieved from https:// eng.brics-russia2020.ru/news/20201015/852498/Experts-discuss-Concept-offunctioning-and-development-as-well-as-Roadmap-for-BRICS-Network.html 
Cheng, J. (2020). BRICS Students Education in China from 2010 to 2018: Development, Problems and Recommendations. Conjuntura Asutral, 11(53), 67-91. doi: $10.22456 / 2178-8839.96259$

Finardi, U. and Buratti, A. (2016). Scientific collaboration framework of BRICS countries: an analysis of international coauthorship. Scientometrics, 109, 433-446. doi: 10.1007/s11192-016-1927-0

Flick, U. (2009). An Introduction to Qualitative Research. London: Sage.

Henan Education Association for International Exchange (2018). North China University of Water Resources and Electric Power. Retrieved from http://www.hneaie.com/ article/643.html

Hernández, J. C. and Bui, Q.(2018). The American Dream Is Alive. In China. Retrieved from https://www.nytimes.com/interactive/2018/11/18/world/asia/china-socialmobility.html

Khomyakov, M. B. (2018). BRICS and Global South: Towards Multilateral Educational Collaboration. Changing Societies \& Personalities, 2(4), 329-350. doi:10.15826/ csp.2018.2.4.050

Khomyakov, M., Dwyer, T., and Weller, W. (2020). Internationalization of higher education: excellence or network building? What do BRICS countries need most? Sociologias, 22(54), 120-143. doi: 10.1590/15174522-99066

Khomyakov, M., Panova, V., Piskulova, N. and Abramova, A. (2015). BRICS: a new multilateral entity. Report to the BRICS Global University Summit. Retrieved from http://gusbrics.mgimo.ru/doc/gusbrics-report.pdf

Kovalev, I. and Shcherbakova, A. (2019). BRICS Cooperation in Science and Education. Strategic Analysis, 43(6), 532-542. doi:10.1080/09700161.2019.1669903

Kowal, S. and O'Connell, D. C. (2014). Transcription as a Crucial Step of Data Analysis. In U. Flick (Ed.). The SAGE Handbook of Qualitative Data Analysis(7o). London: Sage.

Kuckartz, U. (2014). Qualitative Text Analysis. A Guide to Methods, Practive \& Using Software. London: Sage, 69-88.

Li, Y. (2018). Development of Cooperation in Higher Education in BRICS Countries. Changing Societies \& Personalities, 2(4), 393-405. doi:10.15826/csp.2018.2.4.053

Liu, Y. (2015). Mapping the research collaboration between BRICS countries during 2001-2012 using co-authorships. Global Science, Technology and Economy Outlook, 3o(2), 67-75. doi: 10. 3772 / j. issn.1009-8623.2015.02.010

Muhr, T., and Azevedo, M. D. (2018). The BRICS development and education cooperation agenda. Vestnik RUDN. International Relations, 18(3), 517-534. doi: 10.22363/2313-0660-2018-18-3-517-534 
O’Neill, J. (2001). Building Better Global Economic BRICs. Goldman Sachs Global Economics Paper. Retrieved from https://www.goldmansachs.com/insights/ archive/archive-pdfs/build-better-brics.pdf

Oleksiyenko, A. and Yang, R. (2015) Nix the BRICs? Competitive and Collaborative Forces in the Ostensibly "Blocalized" Higher Education Systems. Frontiers of Education in China, 1O(1), 1-6. doi:10.3868/s110-004-015-0001-3

Rensburg, I., Motala, S. and David, S.A. (2015). Learning mobility and internationalisation of higher education: economic and policy implications for BRICS nations. Education Economics and Development, 6(3), 262-277. doi:10.1504/IJEED.2015.073164

Rensburg, I., Motala, S. and David, S.A. (2016). Research collaboration among emerging economies: policy and economic implications for BRICS nations. International Journal of Economic Policy in Emerging Economies, 9(4), 344-360. doi: 10.1504/ IJEPEE.2016.10002394

Schreier, M. (2018). Sampling and Generalization. In U. Flick (Ed.).The SAGE Handbook of Qualitative Data Collection(88). London: Sage.

Schriewer, J. (1988). The Method of Comparison and the Need for Externalization: Methodological Criteria and Sociological Concepts. In Schriewer, J. Brian Holmes (Ed.). Theories and Methods in Comparative Education(40). Frankfurt am Main: Peter Lang.

Singh, K. (2017). BRICS and Mortar: New Architecture in Education. Occasional Publication, 83.

Smagina, I. (2016). Conference review notes the first forum of the Brics Network University. BRICS law journal, 3(1), 144-151. doi:10.21684/2412-2343-2016-3-1144-151

University of Toronto. BRICS Information Center (2009). Joint Statement of the BRIC Countries' Leaders Yekaterinburg, Russia, June 16, 2009. Retrieved from http:// www.brics.utoronto.ca/docs/index.html

University of Toronto. BRICS Information Center(2011). Sanya Declaration. Sanya, Hainan, China, April 14, 2011. Retrieved from http://www.brics.utoronto.ca/ docs/110414-leaders.html

University of Toronto. BRICS Information Center(2020). BRICS Official Documents and Meetings. Retrieved from http://www.brics.utoronto.ca/docs/index. html\# education

Varghese, N. V. (2015). BRICS and International Collaborations in Higher Education in India. Frontiers of Education in China, 10(1), 46-65. doi: 10.3868/s110-004-0150004-4

Wang, X. L., Liu, J. and Sun, J. (2018) Bibliometric analysis of scientific and technological cooperation papers of BRICS countries. China Science \& Technology Resources Review (China), 5o(3), 87-93. doi:10.3772/j.issn.1674-1544.2018.03.013

Xinhua Net (2020). Full text of BRICS Summit Moscow Declaration. Retrieved from http://www.xinhuanet.com/english/2020-11/17/c_139523088.htm 